\title{
Q methodological study on stakeholder involvement processes that support process use of evaluation in the Upper Regions, Ghana
}

\author{
Bernard Afiik Akanpabadai Akanbang \\ Senior Lecturer \\ Department of Planning \\ University for Development Studies, Wa Campus, Ghana \\ E-mail: bakanbang@uds.edu.gh \\ Gordon Dugle \\ Lecturer \\ Department of Management Studies \\ School of Business and Law \\ University for Development Studies, Wa Campus, Ghana \\ duglegordon@gmail.com

\section{Millicent Awialie Akaateba} \\ Lecturer \\ Department of Planning \\ University for Development Studies, Wa Campus, Ghana \\ makaateba@uds.edu.gh
}

Submitted: May 31, 2018/ Accepted: December 2, 2019/ Published: December 30, 2019

\begin{abstract}
This paper uses Q Methodology to ascertain the views of project staff on how they could be involved in evaluation in order to enhance process use. Structured interviews were conducted with twenty-five project staff who participated in two project evaluations within the context of participatory evaluation in Ghana. It emerged that the use of Q Methodology in evaluation studies enhances the mainstreaming of process use by helping to focus on the critical issues in participatory evaluation practice. Process use is enhanced when ample time is provided for intensive interaction with evaluation stakeholders from the formative stage of evaluation. Process use also requires evaluators to create an environment that is supportive of mutual interaction and closeness in working relations with stakeholders. The research concludes that process use in evaluation is attained through well-planned evaluation that gives voice to project staff and emphasises shared learning. The study recommends critical attention to active participation of project staff, group processes and shared learning, if process use is to be achieved by evaluation. Further research is needed to clarify which form(s) of stakeholder involvement in evaluations contributes more positively to process use.
\end{abstract}

Keywords: evaluation, stakeholder involvement, process use, Q methodology 


\section{Introduction}

The involvement of multiple stakeholders in evaluation has been widely acknowledged (Akanbang, Darko \& Atengdem, 2013b; Smits \& Champagene, 2008). For instance, participatory evaluation is noted to facilitate: stakeholder empowerment (Harnar \& Preskill, 2007; King, 2007; Suárez-Herrera et al., 2009), increased use of evaluation results (Bryson, Patton, \& Bowman, 2011; Cornachione, Trombetta, \& Nova, 2010; Patton, 2008; Podems, 2007; Smits \& Champagne, 2008; Suárez-Herrera et al., 2009); sense of ownership and commitment to the evaluation and provision of opportunities for learning about effective evaluation practice (Preskill, Zuckerman \& Matthews, 2003). What is however unclear in the participatory evaluation discourse is the form of stakeholder involvement in evaluation that is required for it to positively influence process use ( Harnar \& Preskill, 2007).

From the early 2000s, Ghana began to promote evaluation as part of its poverty reduction efforts. The national approach to evaluation is anchored on participatory monitoring in which ensuring a high level of awareness and participation by the citizenry in evaluation processes is advocated. Thus, participatory data collection, collation and use are integral to the monitoring and evaluation process. Citizenryservice providers' interfaces have been provided and implemented as part of pilot projects in order to improve upon service delivery (International Monetary Fund, 2009).

The prominence given to process use of evaluation in the past two decades has created renewed interest in exploring stakeholder involvement in evaluations (Akanbang, Darko \& Atengdem, 2013a; Amo \& Cousins, 2007; Baptiste, 2010; Bryson, Patton \& Bowman, 2011; Harnar \& Preskill, 2007). Process use of evaluation is one of the key ways of enhancing evaluation utilisation (Amo \& Cousins, 2007; King, 2007; Patton, 2008, Podems, 2007). Its emergence at a time that evaluation has come under criticism for not contributing enough to the attainment of project objectives (Bambeger, 2009; House, 2008) makes it a contemporary discourse.

This paper presents evidence on the form of stakeholder participation that is required to enhance process use in evaluation. It contributes to the literature and the search for ways of enhancing process use by examining the views of project staff involved in participatory evaluation in Ghana. The question explored in the study is "what processes of stakeholder involvement in evaluation are required for it to positively impact on process use?" As underscored by Harnar and Preskill (2007), there is consensus on the need for stakeholder involvement in evaluation, but the form and process of involvement required to attain process use remain unclear. Many evaluations do not commit ample time and financial resources to cater for 
the painstaking consultations and dialoguing needed for stakeholder participation (Bamberger, Rugh, \& Mabry, 2006; Bryson \& Patton, 2010; Bryson, Patton \& Bowman, 2011). The rise in results-based management coupled with the desire to show value for money has also jeopardized substantial involvement of stakeholders in evaluation (Bryson et al., 2011). There is therefore the need for evidence not just to support stakeholder involvement in evaluation but to reveal the processes and forms of involvement that will yield optimal impact on process use. By focusing on the perspective of project staff (demand side of evaluation), the study brings new perspectives to the discussion which has largely reflected the perspectives of evaluators (supply side of evaluation).

\section{Theoretical Framework}

\section{Stakeholder involvement in evaluation}

Traditionally, monitoring and evaluation (M\&E) have been viewed as important processes for improving development planning, service delivery, demonstrating results, and for learning (UNDP, 2009). Since the 1980s, efforts to involve stakeholders directly affected by development activities to make an input into the evaluation have intensified (Ofosu \& Ntiamoah, 2016; Estrella, 2000; Vernooy, 2005). The introduction of participation into $M \& E$ is traced to participatory research traditions (Matsiliza, 2012; Vernooy, 2005). The growing interest in performance-based accountability beyond financial reporting; as well as the shift towards decentralisation and devolution of central government responsibilities and authority to lower levels of government have contributed to the interest in participatory monitoring and evaluation (Hope, 2008; Speer, 2012; Estrella, 2000).

Participatory M\&E is largely based on two perspectives - participation as a means (process of participation) and participation as an end (effect or benefits of participation) (Vernooy, 2005). According to Matsiliza (2012), Participatory M\&E is an active engagement and judgment process through which different levels of stakeholders engage in monitoring and evaluation of a project. Among the key features of participatory monitoring and evaluation (PM\&E) are: building capacity of local people to analyse, reflect and take action; enabling people to reflect on their experiences together; being flexible and adaptive to local contexts; encouraging stakeholder participation beyond data gathering and strengthening people's capacities to take action and promote change (Estrella, 2000; Mascia, Pailler, Thieme, Rowe, Bottrill, Danielsen \& Burgess, 2014; Matsiliza, 2012). In this paper, we adopt the definition of stakeholder involvement in evaluation by Jones, Young and Stanley (2004). They define stakeholder involvement in evaluation as 'making key stakeholders to become integrally involved in setting up the systems for measuring and reporting on results, reflecting on results achieved, proposing solutions and responding to challenges, and promoting the implementation of evaluation recommendations' ( $\mathrm{p} 30$ ). 
In spite of the benefits associated with stakeholder involvement in evaluation, the level of involvement of stakeholders in evaluation is still a matter of debate and controversy among the evaluation community (Akanbang, Dugle \& Yakubu, 2016; Donaldson, Patton, Fetterman. \& Scriven, 2010).

\section{Process use}

The goal of PM\&E is not simply the creation of an M\&E capability, but the use of performance information to assist in improving project planning and management. Evaluation use is thus central to participatory monitoring and evaluation. Evaluation use, defined as the application of evaluation processes, products, findings to produce an effect (Johnson et al., 2009), has been a long subject of interest to evaluation researchers, policy makers and practitioners (Akanbang, Yakubu \& Akaateba, 2015; Hyyrylainen \& Viinamaki, 2008). Evaluation use is considered a central outcome of any evaluation, because without it, evaluation cannot contribute to social betterment (Henry \& Mark, 2003; Patton, 2008). Research on evaluation use has traditionally been limited to use of findings divided into three types: instrumental, conceptual and symbolic use (Akanbang, Yakubu \& Akaateba, 2015; Amo \& Cousins, 2007; Fleischer \& Christie, 2009; Hyyrylainen \& Viinamaki, 2008). Patton, in 1997, is believed to have coined process use as "use category of evaluation". Since then, a lot of interest has grown over the subject (see Akanbang, Osei-Darko \&Atendem, 2013a \& b, Forss et al., 2002; Amo \& Cousins, 2007; Harnar \& Preskill, 2007; Podems, 2007; Henry \& Mark, 2003; Johnson et al., 2009; Baptist, 2010). Patton, later in 2008, defined process use as including:

cognitive, attitudinal and behaviour changes in individuals, and programme or organisational changes resulting, either directly or indirectly from engagement in the evaluation process and learning to think evaluatively (e.g., increased evaluation capacity, integrating evaluation into the programme, goals clarification, conceptualizing the programme's logic model, setting evaluation priorities, improving outcomes measurement). (Patton, 2008, p. 156)

Forss, Rebien and Carlsson (2002) argued that evaluation commissioners and evaluators should work explicitly to increase process use as the most cost effective way of strengthening the overall utility of an evaluation. Process use makes an evaluation to become part of the treatment, rather than just being an independent assessment of effects.

The definition of process use by Akanbang et al. (2013b) is adopted in this paper. They define process use as 'uses that occur and result in programme enhancement and organisational learning as a result of programme participants' involvement in and learning from the evaluation process. It is indicated by changes in individuals' knowledge and behaviour, changes in programme design 
Agyeman, N.A./Q methodological study on stakeholder involvement processes that support process use of evaluation in the Upper Regions, Ghana

and operations and changes in organisational procedures resulting directly from evaluation process and not the evaluation findings' (p. 2).

\section{Context to the study}

This paper is based upon the experiences of project staff of two project evaluations, Small Towns Water Supply and Sanitation Project (STWSSP) and the Community Based Health Planning Services CHPS), in a zone that piloted the decentralised M\&E system developed by the National Development Planning Commission of Ghana. The STWSSP is a US\$ 26 million Project that was funded by the World Bank. The Project initially spanned November, 2004 and April, 2009 but with some amendment and additional funds to the tune of US\$10m in 2007 and US\$ $15 \mathrm{~m}$ in 2009, the project was extended by one year. The Project was implemented in seventy-two communities in forty-two districts in six regions of Ghana - Upper East, Upper West, Brong-Ahafo, Ashanti, Central and Western Regions. An evaluation in the first quarter of 2011 was conducted in four districts (Bongo and Garu in the Upper East and Wa and Lawra in the Upper West) out of twelve districts in the six project regions. Monitoring and evaluation was an integral part of project management. Project progress monitoring was undertaken mainly in the form of field visits to sites of projects to ensure compliance and immediate feedback for project improvement. At the technical level, monitoring tracked the extent to which the project delivered the expected quantity and quality of outputs. At the administrative level, monitoring tracked capacity of staff to deliver results, use of resources and equipment and the extent to which workplans and schedules were adhered to. Quarterly reviews, mid-year reviews and annual reviews were an integral part of the project evaluation and provided platforms for actors to assess the progress of the project, identify obstacles to project implementation and reach consensus on the way forward for successful project completion.

CHPS project is a US\$ 4.8 million project with funding support from the Japanese International Development Cooperation (JICA). Spanning March 2006 and February 2010, it aimed at strengthening community participation in health planning and service provision; and strengthening of monitoring and supervision at all levels of health services delivery in the Upper West Region. Evaluation under the project had a two-fold purpose: learning for project enhancement, and upward accountability to the financier.

This study limited itself to process use in evaluation in the two projects in the Upper West and East Regions because the two regions belonged to a context in which NDPC framework for decentralised participatory monitoring and evaluation was piloted. 


\section{Methods}

The study was conducted between April 2011 and October, 2012. A survey of all ongoing and completed projects in the Upper East and West Regions between the period 2000 and 2010 was undertaken. Two projects were then purposively selected because they adopted participatory evaluation process; and had at least ten participants in the evaluation still at post to participate in the study. The study participants were all staff who were involved in the implementation of the projects and participated in their evaluation and were still at post. In Q Methodology, participants are selected not to provide an accurate mirror of the population but to enable them communicate their views (Watts \& Stenner, 2012).

The study participants for the CHPS project consisted of three staff at the project office, three regional deputy directors, two district health directors and two staff in-charge of the CHPS compounds who were directly involved in the implementation and evaluation of the project. Respondents from the STWSSP included two extension staff, two MIS officers, and one of the accountants of the Community Water and Sanitation Agency in the Upper East and West Regions; four district schedule officers for water and sanitation; four team leaders of the district water and sanitation teams; and two water board chairmen. Respondents had been working on the projects for five years and participated in at least three evaluations.

The study employed Q methodology in collecting and analysing the data. Q Methodology is a mixed-methodological approach rooted in constructivism (Boroş, Visu-Petra \& Cheie, 2007; Danielson, 2009; Ward, 2010). The methodology provides flexible procedures for the examination of subjectivity within an operant framework. In an operant approach, the subjects of the study in their natural state are allowed to speak for themselves. Q Methodology leans more towards qualitative methods at the point of data collection but gets more quantitative at the point of analysis (Brown, Durning, \& Selden, 2008; Watts \& Stenner, 2012). Q Methodology is suitable for in-depth analysis of small number of cases. It is these unique strengths of the methodology that recommended itself to this study in relation to other qualitative methods or even $\mathrm{R}$ Methodology. We were interested in capturing the subjective experiences of staff involved in the implementation and evaluation of community development projects. The views of project beneficiaries were not considered in the study because we wanted to avoid complications associated with Q Methodology, such as the administration of the Q Sort to illiterate populations. The study also found it complicated to use pictures to represent the different statements that constitute the Q Sample to make the sorting process easier for illiterate populations. 
Agyeman, N.A./Q methodological study on stakeholder involvement processes that support process use of evaluation in the Upper Regions, Ghana

Besides, the study participants were few and it was inappropriate to use conventional factor analysis which requires a large sample size for statistical power (Watts \& Stenner, 2012). The study is focused on the identification of themes in stakeholder evaluation approaches and not on consensus, as is the case with traditional factor analysis. In addition, Q Methodology was preferred over other qualitative methods such as focus group discussions and in-depth interviews in this study because it allowed for quantitative analysis of the data and for easy identification of patterns across persons which is not possible with the other qualitative methods. Subjectivity runs through all the stages of a Q study, yet the factors are usually reliable and easily replicated, and are subject to statistical summary which facilitates more careful description and comparison.

Q Methodology is distinct from R Methodology in that the latter studies relationships among objective variables while the former studies relationships between persons. Notwithstanding these strengths of Q Methodology, it is not a very popular methodology in participatory evaluation studies, even though, it has grown over time and is widely used in psychology, political science and in the social and health sciences (Danielson, 2009). Its use in this study thus expands the methodological scope of evaluation studies. The following Q Methodology procedures were used: generation of ideas about the research topic (Concourse), generation of Q Samples, generation of Person Samples, development of Q sort and analysis of results (van Exel \& de Graaf, 2005; Webler, Danielson, \& Tuler, 2009). These stages and procedures are discussed in detail in BoroŞ, Visu-Petra and Cheie (2007), van Exel and de Graaf (2005), and Webler, Danielson and Tuler (2009).

The concourse of this paper was derived from reported statements in published literature about what constitutes the form of stakeholder involvement processes required for process use of evaluation. Specifically, the works of Bryson et al. (2011), Cornachione et al. (2010), Estrella and Gaventa (1998), Rossi et al. (2004), Smits and Champagne (2008) were the main sources of information for this concourse. In all 25 statements were generated from the literature to constitute the concourse for this study. Our Q Sample was generated by subjecting the concourse statements to field test among five staff of the two projects to find out how the statements represented the perception of evaluation stakeholders. The field test helped to refine statements that were initially not clear to evaluation stakeholders. All the 25 refined statements constituted the Q Sample. The question of bias does not arise in the constitution of the Q Sample in the study because the concourse is representative of all viewpoints on the subject. The Q Sample is represented in Table 1. 
Table 1: Q Sample

\begin{tabular}{|c|c|}
\hline No. & Statement \\
\hline 1 & $\begin{array}{l}\text { The evaluator needs not consult with stakeholders to describe the evaluation, their } \\
\text { willingness to participate and their potential involvement in order to promote } \\
\text { process use }\end{array}$ \\
\hline 2 & $\begin{array}{l}\text { Evaluation managers need to inform stakeholders about the evaluation, describe } \\
\text { its broad parameters, identify the evaluator and initiate dialogue in order to } \\
\text { enhance process use }\end{array}$ \\
\hline 3 & $\begin{array}{l}\text { Brainstorming solutions with participating organisations/individuals promote } \\
\text { process use }\end{array}$ \\
\hline 4 & $\begin{array}{l}\text { Stimulating sharing and expressing multiple standpoints benefit collective } \\
\text { comprehension }\end{array}$ \\
\hline 5 & $\begin{array}{l}\text { Following-up to determine whether decision-making is informed by evaluation } \\
\text { constitutes an interference with management's work and is not required to ensure } \\
\text { process use }\end{array}$ \\
\hline 6 & $\begin{array}{l}\text { Organising the evaluation at a time that allows it to affect project decisions } \\
\text { encourages participation and facilitates process use }\end{array}$ \\
\hline 7 & $\begin{array}{l}\text { Constantly keeping stakeholders informed of their expectations and developments } \\
\text { promotes process use }\end{array}$ \\
\hline 8 & $\begin{array}{l}\text { A well formulated strategy for stakeholders' participation is enough to ensure } \\
\text { process use }\end{array}$ \\
\hline 9 & The neglect of cultural sensitivity in an evaluation imperils process use \\
\hline 10 & $\begin{array}{l}\text { The evaluator's ability to build and sustain interests of stakeholders in the use of } \\
\text { the evaluation determine whether process use occurs or not }\end{array}$ \\
\hline 11 & $\begin{array}{l}\text { When stakeholders are provided with a guided journey of discovery that } \\
\text { emphasises the learning process, process use is guaranteed }\end{array}$ \\
\hline 12 & $\begin{array}{l}\text { Assessing the information needs of stakeholder groups and gauging their potential } \\
\text { level of commitment does not bring any difference to the use of evaluations }\end{array}$ \\
\hline 13 & $\begin{array}{l}\text { Ensuring that all key stakeholders have access to information on the evaluation at } \\
\text { every stage enhances process use occurrence }\end{array}$ \\
\hline 14 & $\begin{array}{l}\text { When findings are presented using theatre, skits or video, evaluation findings are } \\
\text { trivialised and therefore lose their value and seriousness }\end{array}$ \\
\hline 15 & $\begin{array}{l}\text { When friendly, open and frank discussions, while respecting differing opinions } \\
\text { and individual sensitivities are encouraged by the evaluator, process use is } \\
\text { enhanced }\end{array}$ \\
\hline 16 & $\begin{array}{l}\text { Evaluators need not reach decisions with the staff and management about the } \\
\text { implications of the analysed information in order to promote process use }\end{array}$ \\
\hline 17 & $\begin{array}{l}\text { The evaluator from the design stage of the evaluation engages stakeholders on } \\
\text { obstacles and opportunities to enhance process use }\end{array}$ \\
\hline
\end{tabular}


Agyeman, N.A./Q methodological study on stakeholder involvement processes that support process use of evaluation in the Upper Regions, Ghana

\begin{tabular}{|l|l|}
\hline 18 & $\begin{array}{l}\text { Packaging and disseminating evaluation findings bearing in mind the needs of the } \\
\text { different stakeholders enhances process use }\end{array}$ \\
\hline 19 & $\begin{array}{l}\text { The use of pre-departure debriefings on initial findings is as weak as the effect of } \\
\text { the main evaluation report in influencing process use }\end{array}$ \\
\hline 20 & $\begin{array}{l}\text { Use of focus groups as medium of data collection will not yield any learning as } \\
\text { only a few people will capture the discussions }\end{array}$ \\
\hline 21 & $\begin{array}{l}\text { Evaluators without people skills (e.g. building relationships, facilitating groups, } \\
\text { managing conflicts) cannot facilitate process use }\end{array}$ \\
\hline 22 & $\begin{array}{l}\text { Involving stakeholders and participants in an evaluation process, focusing on } \\
\text { issues that are relevant for them, increases process use }\end{array}$ \\
\hline 23 & $\begin{array}{l}\text { Involving stakeholders who have an interest and want to know something more } \\
\text { about the programme enhances process use of evaluations }\end{array}$ \\
\hline 24 & $\begin{array}{l}\text { Helping key stakeholders to avoid attaching their egos to the outcome of the } \\
\text { evaluations encourages genuine participation and process use }\end{array}$ \\
\hline 25 & $\begin{array}{l}\text { Discussion of evaluation findings as a group enhances the process use of the } \\
\text { evaluation }\end{array}$ \\
\hline
\end{tabular}

Source: Authors' Construct, 2011

The target population is composed of all evaluation participants of the two project evaluations in the Upper West and East regions. All participants of the population were expected to be interviewed. Snowballing was used to reach participants as a sample frame of participants was not readily available. A total of twenty-five (10 from CHPs and 15 from STWSSP) respondents participated in the study.

A Q sort is a special questionnaire used in Q studies. The shape of the Sort is a quasi-normal distribution while the kurtosis of the distribution depends on the nature of controversy surrounding the topic. Studies where involvement, interest or knowledge of respondents is expected to be low, the distribution is steeper in order to leave room for ambiguity, indecisiveness or error in the middle of the distribution. However, in studies where respondents have well-articulated opinions on the topic, the distribution is flatter in order to provide more room for strong (dis)agreement with statements. In this study, steeper distribution was selected because process use is still an emerging concept and relatively new to most evaluation participants. Our Q Sort consisted of a pack of 25 randomly numbered cards (number of cards in a pack corresponds to the number of statements in the $\mathrm{Q}$ Sample). Each card contains one statement of the Q sample. The cards were what participants sorted. Cards were printed on heavy paper using a legible font type and size and cut into uniform sizes. They were then bound together with an elastic band. The pack also 
included a guide, a score sheet containing the distribution for the Q sorting task, and a list of instructions on how respondents were to rank the statements. The score sheet was a single page containing the question that was to be addressed at the bottom and answer spaces above as shown in Table 2. The Q Sort includes a rating scale across the top that can range from -3 to 3 to -6 to 6 (Akhtar-Danesh et al., 2008). Tracking questions such as name, age, educational qualification, and experience with evaluation, among others were put on a different page. The Q Sorts were administered to individual participants in a solo setting. Up to 30 minutes was allocated for the completion of each Q Sort. A sample of the Q-Sort Table is shown in Table 2.

Table 2: Q Sort Table to be completed

\begin{tabular}{|c|c|c|c|c|c|c|}
\hline \multicolumn{3}{|c|}{ Strongly Disagree } & \multicolumn{2}{|c|}{ Neutral } & \multicolumn{2}{|c|}{ Strongly Agree } \\
\hline-3 & -2 & -1 & 0 & +1 & +2 & +3 \\
\hline & & & & & & \\
\hline & & & & & & \\
\hline & & & & & & \\
\hline & & & & & & \\
\hline & & & & & & \\
\hline & & & & & & \\
\hline & & & & & & \\
\hline
\end{tabular}

Which of the statements in the pack about the form of stakeholder participation in evaluation that supports process use do you strongly agree with or strongly disagree with? EXPLAIN CHOICE (-3)

EXPLAIN CHOICE $(+3)$

Principal Component Analysis (PCA) within the Q Methodology software (PQ Method) was used to analyse the data. PCA produces eigenvalues for each factor, which helps in deciding on the number of factors to consider for further analysis. Eigenvalues are a measure of the relative contribution of a factor to the explanation of the total variance in the correlation matrix. For a factor to be significant, it must have an eigenvalue of 1 and above, have at least two people significantly loading on it. A factor loading is significant at 0.01 level, if it exceeds 2.58 of the Standard Error (SE) where standard error (SE) is defined as SE = $1 / \sqrt{ } \mathrm{N}$, where ' $\mathrm{N}$ ' is the Q Sample (Brown, 1980 cited in Akanbang, 2013a). A factor loading expresses the extent to which each Q sort is associated with each 
factor. Factor interpretation is about generating descriptions of social perspectives contained in each factor. Three outputs of the analysis (distinguishing statements, normalised factor scores, and consensus statements) are relevant in interpreting the perspectives. Each perspective is interpreted using the distinguishing statements (Watts \& Stenner, 2012). A distinguishing statement for a perspective is a statement that its score on that perspective is significantly different from its score on any other perspective. The highest-ranking statements are those that loaders on the perspective said were most like how they think, while the lowly-ranked statements indicate the issues that the participants felt were less like how they think (' 3 ' were highly ranked, '0' neutral and ' -3 ' lowly ranked). These high and low ranked statements were weaved together into an explanation of how people who loaded highly on this factor saw the subject matter. A distinguishing table or a consensus table has three main components as shown in Table 5 (the numeric number assigned to the statement in the Q Sample, the statement itself and the ranking given to the statement). Comments made by the $\mathrm{Q}$ participants during the $\mathrm{Q}$ sorting process were used to aid in the factor interpretation. The accuracy of the interpretation was verified by asking the relevant (significantly loaded) participants to comment on their views about the theme of the study.

\section{Results}

Three perspectives on the form and processes of involving stakeholders in evaluation to enhance the occurrence of process use emerged from the study. These perspectives were found to be acceptable because each of them had more than the minimum number of loadings required to meet the composite reliability of 0.95 (Akhtar-Danesh et al., 2008). The correlations between the factors were also low, an indication that the factors were uniquely defined. Table 3 shows the factor characteristics while Table 4 shows the correlation between the factors.

Table 3: Factor Characteristics

\begin{tabular}{|l|l|l|l|}
\hline & Factors & & \\
\cline { 2 - 4 } & 1 & 2 & 3 \\
\hline No. of Defining Variables & 7 & 8 & 5 \\
\hline Average Rel. Coef. & 0.8 & 0.8 & 0.8 \\
\hline Composite Reliability & 0.966 & 0.97 & 0.952 \\
\hline S.E. of Factor Scores & 0.186 & 0.174 & 0.218 \\
\hline
\end{tabular}


Source: Analysis of Field Data, 2011

Table 4: Correlations between Factor Scores

\begin{tabular}{|l|l|l|l|}
\hline & 1 & 2 & 3 \\
\hline 1 & & 0.3392 & 0.3366 \\
\hline 2 & & & 0.4001 \\
\hline 3 & & & \\
\hline
\end{tabular}

Source: Analysis of Field Data, 2011

Factor 1, labelled as "early involvement and information flow perspective" had seven respondents identifying with it while factor 2, defined as "who to involve and use of group processes perspective" had eight respondents loading on it. Factor 3, labelled as "evaluator as a facilitator" group had five respondents loading on it.

\section{Factor 1: Early involvement and information flow perspective}

The perspective held by this factor is illustrated in Table 5. Out of seven respondents who loaded on the factor, five were from the STWSSP. As captured in Table 5, this group perceives the stage of the evaluation process at which stakeholders were involved as very important to the occurrence of process use. In addition, there was the need for flow of information in an environment of respect, openness and frankness in the evaluation process. At the onset of the evaluation, project managers were expected to brief staff of the evaluation on its purpose and processes.

Table 5: Statements that illustrate early involvement and information flow perspective

\begin{tabular}{|l|l|l|}
\hline No. & Statement & Rank \\
\hline 2 & $\begin{array}{l}\text { Evaluation managers need to inform stakeholders about the } \\
\text { evaluation, describe its broad parameters, identify the evaluator } \\
\text { and initiate dialogue in order to enhance process use }\end{array}$ & 3 \\
\hline 7 & $\begin{array}{l}\text { Constantly keeping stakeholders informed of their expectations } \\
\text { and developments is a way of promoting process use }\end{array}$ & 2 \\
\hline 6 & $\begin{array}{l}\text { Organising the evaluation at a time that allows it to affect project } \\
\text { decisions encourages participation and facilitates process use }\end{array}$ & 2 \\
\hline 15 & $\begin{array}{l}\text { When friendly, open and frank discussions, while respecting } \\
\text { differing opinions and individual sensitivities are encouraged by } \\
\text { the evaluator, process use is enhanced }\end{array}$ & 3 \\
\hline
\end{tabular}


Agyeman, N.A./Q methodological study on stakeholder involvement processes that support process use of evaluation in the Upper Regions, Ghana

\begin{tabular}{|l|l|l|}
\hline 21 & $\begin{array}{l}\text { Evaluators without people skills such as building relationships, } \\
\text { facilitating groups, managing conflicts and interpersonal } \\
\text { communication cannot facilitate process use }\end{array}$ & 1 \\
\hline 18 & $\begin{array}{l}\text { Packaging and disseminating evaluation findings bearing in mind } \\
\text { the needs of the different stakeholders enhances process use }\end{array}$ & -1 \\
\hline 13 & $\begin{array}{l}\text { Ensuring that all key stakeholders have access to information on } \\
\text { the evaluation at every stage enhances process use occurrence }\end{array}$ & -1 \\
\hline 25 & $\begin{array}{l}\text { Discussion of evaluation findings as a group enhances the process } \\
\text { use of the evaluation }\end{array}$ & -2 \\
\hline 19 & $\begin{array}{l}\text { The use of pre-departure debriefings on initial findings is as weak } \\
\text { as the effect of the main evaluation report in influencing process } \\
\text { use }\end{array}$ & -3 \\
\hline
\end{tabular}

Source: Analysis of Field Data, 2011

Comments from three participants who identified with this perspective clarify why they think stakeholders should be involved at the early stage of evaluation.

The whole evaluation process should be discussed with management for the evaluator to understand issues from the onset. Evaluators need to know the cultural values of the key stakeholders so as to obtain their cooperation and meaningful contributions in the process. If stakeholders do not understand the purpose of the evaluation, they may not cooperate and key information may not be discussed" (Deputy Regional Director of Health Services, Public Health, 03.05.2011)

"Stakeholder consultation is very important and needs to be done early to ascertain their willingness and ability to participate in the process. (Extension Officer, CWSA, 11.05.2011)

Besides the stage of involvement and manner of information flow, respondents also preferred that evaluation be organised at a time that is suitable to participants as well as meet their information needs. The use of pre-departure debriefings was important to this perspective. Flow of information during the evaluation was also important to this group. It was recognised by the group that this flow of information goes beyond the beginning and end stages of the evaluation. Information flow should be institutionalised throughout the evaluation process. The following comments from respondents who identified with the perspective illustrate their views.

Openness and frankness is a prerequisite to a successful evaluation and learning process. There should not be secrecy in the process. Access to information brings about success in whatever endeavour you want to do. (Chairman, Water and Sanitation Development Board, 16.05.2011) 
Akanbang, B. A. A., Dugle, G. \& Akaateba, M. A./Legon Journal of the Humanities Vol. 30.2 (2019)

In an open and frank environment, learning takes place and all contributors and listeners go home with something new. Also, some salient points that can advance project implementation are brought up. (Information Technology Specialist, Community Water and Sanitation Agency, 10.05.2011)

Cordial relationship with stakeholders and adequate information about the evaluation clears suspicion such as perception of the evaluation being a witch hunting activity. District Budget Officer/District Water and Sanitation Team Schedule Officer, 02.06.2011)

The need for openness as expressed in the above quotes is an indication of the need to provide information to disabuse the minds of participants of their wrong notions about evaluation, and the need to build trust and confidence of the staff in the evaluation process. This way staff would be forthcoming with vital information critical to the success of the evaluation mission.

\section{Factor 2: Who to involve and use of group processes perspective}

The concern of this group was that, the type of evaluation participants and the processes of involving them are important to having an evaluation that can contribute to enhancing process use. Statements contained in Table 6 illustrate the perspective of the group. Stakeholders with strong interest in the project should be involved. To ensure meaningful involvement of stakeholders, it is important to assess the information needs of participants at the beginning of the evaluation. Armed with the information needs of the different stakeholders, the evaluation is better designed, incorporating the identified needs and conducted in a manner that takes into consideration the different contexts and sensibilities of participants. The use of group processes was recognised as essential to evaluation's ability to contribute to process use by the group.

Two respondents of this group gave the following comments to buttress the need for the employment of group processes in evaluations.

Use of group processes enhances cross fertilisation of ideas and it is good for the evaluation. (Water and Sanitation Engineer, CWSA, 11.05.2011)

Discussions offindings as a group is very important as it will afford all stakeholders access to the findings and therefore enhances the use of the evaluation to impact on development outcomes. (Senior Environmental Health Officer, 16.05.2011) 
Agyeman, N.A./Q methodological study on stakeholder involvement processes that support process use of evaluation in the Upper Regions, Ghana

Table 6: Statements Illustrating Factor 2 Perspective

\begin{tabular}{|c|c|c|}
\hline No. & Statement & Rank \\
\hline 23 & $\begin{array}{l}\text { Involving stakeholders who have an interest and want to know } \\
\text { something more about the project enhances process use of evaluations }\end{array}$ & 3 \\
\hline 25 & Discussion of evaluation findings as a group enhances the process use & 3 \\
\hline 15 & $\begin{array}{l}\text { When friendly, open and frank discussions, while respecting differing } \\
\text { opinions and individual sensitivities encouraged by the evaluator, } \\
\text { process use is enhanced }\end{array}$ & 3 \\
\hline 13 & $\begin{array}{l}\text { Ensuring that all key stakeholders have access to information on the } \\
\text { evaluation at every stage enhances process use occurrence }\end{array}$ & 2 \\
\hline 22 & $\begin{array}{l}\text { Involving stakeholders and participants in an evaluation process, } \\
\text { focusing on issues that are relevant for them, increases process use }\end{array}$ & 1 \\
\hline 9 & The neglect of cultural sensitivity in an evaluation imperils process use & 1 \\
\hline 19 & $\begin{array}{l}\text { The use of pre-departure debriefings on initial findings is as weak as the } \\
\text { effect of the main evaluation report in influencing process use }\end{array}$ & 1 \\
\hline 12 & $\begin{array}{l}\text { Assessing the information needs of stakeholder groups and gauging their } \\
\text { potential level of commitment does not bring any difference to the use } \\
\text { of evaluations }\end{array}$ & -2 \\
\hline 5 & $\begin{array}{l}\text { Following-up to determine whether decision-making is informed by } \\
\text { evaluation constitutes an interference with management's work and is } \\
\text { not required to ensure process use }\end{array}$ & -2 \\
\hline 16 & $\begin{array}{l}\text { Evaluators need not reach decisions with the staff and management } \\
\text { about the implications of the analysed information in order to promote } \\
\text { process use }\end{array}$ & -3 \\
\hline
\end{tabular}

Source: Analysis of Field Data, 2011

\section{Factor 3: Evaluator as a facilitator perspective}

In this group, the evaluator's role is appreciated not in terms of the perceived conventional role as an independent technical person, but as a facilitator. Evaluators should provide participants with a guided journey of discovery in which learning and not judgement is the cardinal objective. Evaluators' exit strategy is also very vital while their knowledge and skills in the use of modern techniques in the presentation of findings is also much recognised. Their show of respect for culture and context and the ability to ensure flow of information is critical to carrying the people along in the evaluation process. Similarly, their skills in stimulating sharing and expressing multiple viewpoints are required for facilitating collective understanding and action. The following comments by some of the members of the 
group shed more light on the skills required by evaluators in order to facilitate the conduct of evaluations in ways that impact positively on process use.

People skills such as building relationships with stakeholders are vital to facilitating evaluations that are used to improve upon projects. The dynamic nature of the evaluator as well his/her non-judgmental attitude is essential to the conduct of an evaluation that will affect development outcomes positively. (Deputy Director of Regional Health Service, Administration, 03.05.2011)

Evaluators should know and be sensitive to the cultural values of the key stakeholders if their cooperation and meaningful contribution to the evaluation is to be assured. (Deputy Director of Regional Health Service, Public Health, 03.05.2011) Table 7 sheds more light on the perspectives of the group.

Table 7: Statements Illustrating Factor 3 Perspective

\begin{tabular}{|l|l|l|}
\hline No & Statement & Rank \\
\hline 24 & $\begin{array}{l}\text { Helping key stakeholders to avoid attaching their egos to the outcome of } \\
\text { the evaluations encourages genuine participation and process use }\end{array}$ & 3 \\
\hline 11 & $\begin{array}{l}\text { When stakeholders are provided with a guided journey of discovery that } \\
\text { emphasises the learning process, process use is guaranteed }\end{array}$ & 1 \\
\hline 13 & $\begin{array}{l}\text { Ensuring that all key stakeholders have access to information on the } \\
\text { evaluation at every stage enhances process use occurrence }\end{array}$ & 3 \\
\hline 25 & $\begin{array}{l}\text { Discussion of evaluation findings as a group enhances the process use of } \\
\text { the evaluation }\end{array}$ & 3 \\
\hline 9 & The neglect of cultural sensitivity in an evaluation imperils process use & 2 \\
\hline 4 & $\begin{array}{l}\text { Stimulating sharing and expressing multiple standpoints tend to benefit } \\
\text { collective comprehension of the program }\end{array}$ & 2 \\
\hline 23 & $\begin{array}{l}\text { Involving stakeholders who have an interest and want to know something } \\
\text { more about the project enhances process use of evaluations }\end{array}$ & -1 \\
\hline 19 & $\begin{array}{l}\text { The use of pre-departure debriefings on initial findings is as weak as the } \\
\text { effect of the main evaluation report in influencing process use }\end{array}$ & -1 \\
\hline 21 & $\begin{array}{l}\text { Evaluators without people skills (e.g. building relationships, facilitating } \\
\text { groups, managing conflicts) cannot facilitate process use }\end{array}$ & -2 \\
\hline 14 & $\begin{array}{l}\text { When findings are presented using theatre, skits or video, evaluation } \\
\text { findings are trivialised and therefore lose their value and seriousness }\end{array}$ & -3 \\
\hline
\end{tabular}

Source: Analysis of Field Data, 2011 
Agyeman, N.A./Q methodological study on stakeholder involvement processes that support process use of evaluation in the Upper Regions, Ghana

\section{Perspectives common to the groups}

The need for early consultations with evaluation stakeholders in order to impact process use was shared by all three groups of perspectives. Another common area is the recognition that the stakeholders to be involved in an evaluation must be people who are interested in evaluation.

\section{Discussion of findings}

Who to involve in an evaluation process: This study clearly reveals that it is not enough to know which group(s) of stakeholders to involve, but more crucially, who among a group of stakeholders to involve in an evaluation. It is important to involve staff who have particular need for the evaluation information. The involvement of such stakeholders is very important especially among public organisations where evaluation is seen as an add-on activity as observed by Akanbang, Yakubu and Dugle (2016). Evaluation guidelines of organisations should therefore state the specific individuals within a category of stakeholders to be involved in an evaluation. Evaluation research on identifying these specific individuals is required to aid evaluation policy of organisations.

Early involvement of staff in the evaluation process: early involvement in the process is important in ensuring buy-in and ownership of the evaluation process. Initial briefings to staff about the evaluation will ignite a deep thinking process in the staff about the project being evaluated. During the briefing process, new thoughts and insights may emerge to facilitate the evaluation. Early consultations require explaining the purpose of the evaluation, the role of evaluation in the project and how the evaluation ought to be conducted. The question, however, is how to make ample time for early involvement in evaluation in contexts where it is largely donor driven, time bound, and accountability oriented. Critical as this question is, the study believes that emerging arrangements where project implementers have control of the budget for evaluation as was revealed by Akanbang et al.(2016), offers an opportunity for them to assert themselves and demand an evaluation process that puts them at the centre at the beginning of the evaluation. Donor recipient organisations must mainstream evaluative thinking in all aspects of their work so that they can actively participate and own project evaluation.

The employment of group processes emerged as central to the occurrence of process use. As observed by Preskill et al. (2003), the more occasions project staff have for sharing information, challenging assumptions, asking questions, and publicly reflecting on past experiences, the more likely they are to experience process use. The employment of group processes also allows the evaluator to gain a comprehensive understanding of the project and forge consensus with 
stakeholders on key decisions required for the enhancement of the project. To overcome the low uptake of group processes in evaluation as noted by Akanbang et al. (2016), evaluation policies and guidelines should require projects to form an all-encompassing taskforce for evaluation; as well as group discussion of findings.

Ensuring a functioning communication throughout the evaluation process: this finding of the study highlights the importance of trust in an evaluation that supports process use. A functioning communication would generate continuous interest in participants, thus causing them to reflect on emerging issues from the evaluation. Besides, it would also help to deal with issues of misrepresentations, antagonism and consequently promote acceptance and ownership of the evaluation process and its findings and recommendations. In addition to the usual debriefing meetings with evaluation participants, exchange of email and telephone contacts as well as the establishment of a social media platform purposefully for the evaluation should be encouraged in evaluation.

The role and skill of the evaluator in ensuring process use is highlighted by this paper. Evaluators should not continue to distance themselves from the evaluation process as neutral technical persons. They should be endowed with skills in stimulating, sharing and expressing multiple viewpoints, that are essential to ensuring collective comprehension and action. This implies new calibre of evaluators and therefore professionalization of evaluation in the developing world. Evaluation terms of reference should also clearly state people skills as a requirement of the evaluator.

\section{Conclusion}

In contributing to the evolving literature on the form of stakeholder involvement in evaluation relevant for process use, the study argued, based on a Q Methodology, that involving project staff at the early stages of evaluation, ensuring a functioning communication with them as the evaluation progresses and employing group processes in the evaluation enhance process use. Even though the findings are not significantly new to the evaluation community, the use of Q Methodology has enabled the narrowing of the wide range and diverse perspectives on the stakeholder involvement processes to a few focus areas enabling the formulation and targeting of evaluation processes that facilitate process use. The study concludes that for enhanced process use, a well-planned evaluation process that gives voice to project staff and places emphasis on shared learning is essential. The study therefore recommends critical attention to active participation of project staff, group processes and shared learning, if process use is to be achieved by evaluation. Further research is needed to clarify which form(s) of stakeholder involvement in evaluations contributes more positively to process use. 
Agyeman, N.A./Q methodological study on stakeholder involvement processes that support process use of evaluation in the Upper Regions, Ghana

\section{References}

Akanbang, B. A. A., Darko, R. O., \& Atengdem, P. B. (2013a). Programme Implementers Experiences of Factors Affecting the Occurrence of Process Use in Evaluation in Northern Ghana. Journal of Human Subjectivity, 11(1), 5-27.

Akanbang, B. A. A., Darko, R. O., \& Atengdem, P. B. (2013b). Programme implementers' experiences of process use types in three evaluation contexts in Northern Ghana. Operant Subjectivity, 36(4), 270-292.

Akanbang, B. A. A., Yakubu, I. \& Akaateba, M. (2015) Programme Implementers 'experiences of evaluation use in Northern Ghana. Annals of Humanities and Development Studies, 6(1), 38-63

Akanbang, B. A. A., Yakubu, I., \& Dugle, G. (2016). Evaluation Inquiry in Donor Funded Programmes in Northern Ghana: Experiences of Programme Staff. Ghana Journal of Development Studies, 13(1), 18-40.

Akhtar-Danesh, N., Baumann, A., \& Cordingley, L. (2008). Q-Methodology in nursing research a promising method for the study of subjectivity. Western Journal of Nursing Research, 30(6), 759-773.

Amo, C. and Cousins, B. J. (2007). Going through the process: an examination of the operationalisation of process use in empirical research on evaluation. In B. J. Cousins, (Ed.), Process use in theory, research and practice: new directions for evaluation (pp. 5-26). San Francisco, California.

Bamberger, M. (2009). Enhancing the utilization of evaluations for evidence- based policy-making. In M. Segone (Ed.). Bridging the gap: The role of monitoring and evaluation in evidence-based policy making (pp 99-120). Geneva: Evaluation working papers, No 12

Bamberger, M., Rugh, J. \& Mabry L. (2006). Real world evaluation: Working under budget, time, data and political constraints, Thousand Oaks, CA: Sage.

Baptiste, L. J. C. (2010). 'Process use across evaluation approaches: An application of $\mathrm{Q}$ methodology in programme evaluation': (Doctoral dissertation) Retrieved from rave.ohiolink.edu/etdc/view?acc_num=kent1271093193. Accessed 10.06.2018

Barbosa, J. C., Willoughby, P., Rosenberg, C. A., \& Mrtek, R. G. (1998). Statistical methodology: VII. Q-methodology, a structural analytic approach to medical subjectivity. Academic Emergency Medicine, 5(10), 1032-1040. 
Akanbang, B. A. A., Dugle, G. \& Akaateba, M. A./Legon Journal of the Humanities Vol. 30.2 (2019)

BoroŞ, S., Visu-Petra, L., \& Cheie, L. (2007). A Q-Sort analysis: Investigating the social perception of a chronic disease: Between sympathy and stigma. Cognitie, Creier, Comportament/Cognition, Brain, Behavior, 11(2).

Brown, S. R., Durning, D. W., Selden, S. C. (2008). Q methodology. In G. J. Miller \& K. Yang (Eds.), Handbook of research methods in public administration (pp 721-763). CRC Press.

Bryson, J. M. \& Patton, M. Q. (2010). Analysing and engaging stakeholders. In Wholey, J. S., Hatry, H. P. \& Newcomer, K E. (Eds.). Handbook of practical programme evaluation ( $3^{\text {rd }}$ ed., pp 30-54). San Francisco: John Wiley and Sons.

Bryson, J. M., Patton, M. Q., \& Bowman, R. A. (2011). Working with evaluation stakeholders: A rationale, step-wise approach and toolkit. Evaluation and Program Planning, 34(1), 1-12.

Cornachione, E. B., Trombetta, M. R., \& Nova, S. P. C. (2010). Evaluation use and involvement of internal stakeholders: The case of a new non-degree online program in Brazil. Studies in Educational Evaluation, 36(1), 69-81.

Danielson, S. (2009). Q Method and Surveys: Three Ways to Combine Q and R. Field Methods, 21(3), 219-237.

Donaldson, S.I., Patton, M.Q., Fetterman, D. \& Scriven, M. (2010). The 2009 Claremont debates: The promise and pitfalls of utilisation focused and empowerment evaluation. Journal of Multi-Disciplinary Evaluation, 6 (13), 15-57.

Estrella, M. (2000) An introduction. In M. Estrella, et al. (eds.), Learning from change: Issues and experiences in participatory monitoring and evaluation (pp 1-15). Intermediate Technology Publications

Estrella, M., \& Gaventa, J. (1998). Who counts reality? Participatory monitoring and evaluation: A literature review Brighton: Institute of Development Studies, University of Sussex. IDS Working Paper 70.

Fetterman, D. M. (1998). Empowerment evaluation and the Internet: A synergistic relationship. Current Issues in Education, 1(4), 1-20.

Fleischer, D. N \& Christie, C. A (2009). Evaluation use: Results from a survey of U.S. American Evaluation Association members. American Journal of Evaluation, 30(2), 158-175

Forss, K., Rebien, C. C., \& Carlsson, J. (2002). Process use of evaluations: Types of use that precede lessons learned and feedback. Evaluation, 8(1), 29-45. 
Agyeman, N.A./Q methodological study on stakeholder involvement processes that support process use of evaluation in the Upper Regions, Ghana

Friedman, M. (2005). Trying hard is not good enough: How to practice measurable improvements for customers and communities. Victoria, B.C: Trafford Publishing.

Greene, J. G. (2005). Stakeholder Involvement'. In S. Mathison (Ed.), Encyclopaedia of evaluation. Thousand Oaks: Sage.

Harnar, M. A., \& Preskill, H. (2007). Evaluators' descriptions of process use: An exploratory study. New Directions for Evaluation, 2007(116), 27-44.

Hatry, H. P., Wholey, J. S., \& Newcomer, K. E. (2010). Evaluation challenges, issues and trends. In K. E. Newcomer, H. P. Hatry, \& J. S. Wholey (Eds.), Handbook of practical program evaluation (3rd ed., pp 668-680). San Francisco: John Wiley \& Sons.

Henry, G. T. and Mark, M. M. (2003). Beyond use: understanding evaluation's influence on attitudes and actions. American Journal of Evaluation, 24(3), 293-314.

House, E. R. (2008). Blowback consequences of evaluation for evaluation. American Journal of Evaluation, 29(4), 416-426.

Hyyrylainen, E. \& Viinamaki, O. P. (2008). The implications of the rationality of decision-makers on the utilization of evaluation findings. International Journal of Public Administration, 31(10-11), 1223-1240.

International Monetary Fund. (2009). Ghana: Poverty Reduction Strategy Paper-2006 Annual Progress Report (No. IMF Country Report No. 09/237). Retrieved from https:/www.imf.org/en/Publications/CR/Issues/2016/12/31/ Ghana-Poverty-Reduction-Strategy-Paper-2006-Annual-ProgressReport-23154

Johnson, K., Greenseid, L. O.., Toal, S. A., King, J. A., Lawrenz, F. \& Volkov, B. (2009). Research on evaluation use; A review of the empirical literature from 1986 to 2005. American Journal of Evaluation, 30(3), 377-410.

Jones, R., Young, V., \& Stanley, C. (2004). CIDA evaluation guide. Ottawa: Evaluation Division Performance \& Knowledge Management Branch. Canadian International Development Agency.

Kállay, E. (2007). Q Methodology the investigation of meaning systems in different life-conditions through proverbs. Cognitie, Creier, Comportament/Cognition, Brain, Behaviour, 11(2), 353-369.

King, J. A. (2007). Developing evaluation capacity through process use. New Directions for Evaluation, 2007(116), 45-59. 
Akanbang, B. A. A., Dugle, G. \& Akaateba, M. A./Legon Journal of the Humanities Vol. 30.2 (2019)

Mascia, M. B., Pailler, S., Thieme, M. L., Rowe, A., Bottrill, M. C., Danielsen, F.,\& Burgess, N. D. (2014). Commonalities and complementarities among approaches to conservation monitoring and evaluation. Biological Conservation, 169(2014), 258-267.

Matsiliza, N. (2012) Participatory monitoring and evaluation: Reviewing an inclusive approach in the South Africa's Government wide monitoring and evaluation. Africa's Public Service Delivery and Performance Review, 1(2), 67-83.

Miller, W., \& Lennie, J. (2005). Empowerment evaluation: A practical method for evaluating a national school breakfast program. Evaluation Journal of Australasia, 5(2), 18-26.

Newcomer, K. E., Hatry, H. P., \& Wholey, J. S. (2010). Planning and designing useful evaluations. In J. S. Wholey, H. P. Hatry, \& K. E. Newcomer (Eds.), Handbook of practical program evaluation (3rd ed., pp 5-29). San Francisco: John Wiley \& Sons.

Nicholls, J., Mackenzie, S., \& Somers, A. (2007). Measuring Real Value: A DIY guide to social return on investment. London: New Economics Foundation.

Ofosu, S., \& Ntiamoah, E. B. (2016). Assessing community involvement in monitoring and evaluation of development projects. The case of the Kwahu West Municipal Assembly, Ghana. British Journal of Education, Society and Behavioural Science, 14(1), 1-12.

Patton, M. Q. (2008). Utilization-focused evaluation. Sage publications.

Podems, D. (2007). Process use: A case narrative from Southern Africa. New Directions for Evaluation, 2007(116), 87-97.

Preskill, H., Zuckerman, B., \& Matthews, B. (2003). An exploratory study of process use: Findings and implications for future research. American Journal of Evaluation, 24(4), 423-442.

Rossi, P. H., Lipsey, M. W., \& Freeman, H. E. (2004). Evaluation: A systematic approach. Thousand Oaks: SAGE Publications, Inc.

Smits, P.A., \& Champagne, F. (2008). An assessment of the theoretical underpinnings of practical participatory evaluation. American Journal of Evaluation, 29(4), 427-442.

Speer, J. (2012). Participatory governance reform: a good strategy for increasing government responsiveness and improving public services? World Development, 40(12), 2379-2398. 
Agyeman, N.A./Q methodological study on stakeholder involvement processes that support process use of evaluation in the Upper Regions, Ghana

Suárez-Herrera, J. C., Springett, J., \& Kagan, C. (2009). Critical connections between participatory evaluation, organisational learning and intentional change in pluralistic organisations. Evaluation, 15(3), 321-342.

United Nations Development Programme (2009) Handbook on planning, monitoring and

evaluation for development results. United Nations Development Programme, One United Nations Plaza New York, NY 10017, USA

van Exel, J., \& de Graaf, G. (2005). Q Methodology: A sneak preview. Retrieved from http://blogs.nd.edu/lapseylab/files/2014/10/vanExel.pdf on $9^{\text {th }}$ June, 2010

Vernooy, R. (2005) Participatory monitoring and evaluation: Readings and resources

(Volume $8,2^{\text {nd }}$ edition). The Rural Poverty and Environment Program Initiative, IDRC, Ottawa, Ontario, Canada.

Ward, W. (2010). Q and you: The application of Q Methodology in recreation research. In Watts, C. E., Jr.; Fisher, C. L., (Eds). Proceedings of the 2009 Northeastern Recreation Research Symposium (pp. 75-80). Gen. Tech. Rep. NRS-P-66. Newtown Square, PA: U.S. Department of Agriculture, Forest Service, Northern Research Station.

Watts, S., \& Stenner, P. (2012). Doing Q Methodological research: Theory, method and interpretation. Sage.

Webler, T., Danielson, S., \& Tuler, S. (2009). Using Q method to reveal social perspectives in environmental research. Greenfield MA: Social and Environmental Research Institute, 54, 1-45. 
